\title{
Controle alternativo de nematoide das galhas (Meloidogyne incognita) raça 2, com óleos essenciais em solo
}

\author{
Francisco José Carvalho Moreira ${ }^{1 *}$; Carmem Dolores Gonzaga Santos ${ }^{2}$; Renato Innecco ${ }^{3}$; Gilson Soares da Silva ${ }^{4}$
}

${ }^{1} E^{2} g^{0}$. Agrônomo, MSc., Prof. do Eixo Tecnológico de Recursos Naturais; IFCE - Campus Sobral, (88) 3112-8072. ${ }^{2}$ Enga . Agrônoma. D.Sc. profa. Adjunta do Dep. de Fitotecnia CCA/UFC. carmelo@ufc.br; ${ }^{3}$ Eng $^{\circ}$. Agrônomo. D.Sc. prof. Adjunto do Dep. de Fitotecnia CCA/UFC innecco@ufc. br; ${ }^{4} \mathrm{Eng}^{\circ}$. Agrônomo. D.Sc. prof. Adjunto do Dep. de Fitotecnia e Fitossanidade CCA/UEMA gilson_soares@uol.com.br; *Parte da Dissertação de mestrado do primeiro autor, apresentada ao Departamento de Fitotecnia, da Universidade Federal do Ceará.

Autor para correspondência: Francisco José Carvalho Moreira (franze.moreira@ifce.com.br)

Data de chegada: 23/01/2014. Aceito para publicação em: 29/06/2015.

$10.1590 / 0100-5405 / 1967$

\section{RESUMO}

Moreira, F.J.C.; Santos, C.D.G.; Innecco, R.; Silva, G.S. Controle alternativo de nematoide das galhas (Meloidogyne incognita) raça 2, com óleos essenciais em solo. Summa Phytopathologica, v.41, n.3, p.207-213, 2015.

A ação de produtos naturais sobre fitopatógenos tem sido investigada visando-se avaliar sua eficácia no controle alternativo de doenças, principalmente na agricultura orgânica. O objetivo desse trabalho foi avaliar o efeito dos óleos essenciais de alecrim pimenta (Lippia sidoides) e capim citronela (Cymbopogon winterianus) no controle de Meloidogyne incognita raça 2, em tomate (Solanum lycopersicum) e celósia (Celosia plicata). Para tanto, conduziu-se ensaio em esquema fatorial $6 \times 2$, com cinco repetições. O ensaio foi realizado em casa de vegetação do Setor de Fitossanidade do Departamento de Fitotecnia/CCA/ UFC, no período de abril a junho de 2007. As mudas utilizadas neste ensaio foram transplantadas para vasos plástico contendo $2 \mathrm{~kg}$ de solo estéril, nos quais, 24 horas após o transplantio, foram inoculados com 4.000 ovos/J2 de M. incognita, raça 2, exceto as testemunhas negativas. Em 50\% do número de vasos, aplicou-se, logo em seguida, $100 \mathrm{ml}$ das soluções de cada óleo essencial em cada vaso na concentração de $2,5 \mathrm{ml} \mathrm{L}^{-1}$. Esperaram-se mais 48 horas para aplicação da mesma quantidade nos vasos restantes. Este volume corresponde a $60 \%$ da capacidade de campo desse substrato, que foi previamente calculada. A avaliação final do ensaio deu-se aos 45 dias após a inoculação. Analisou-se em relação ao nematoide: número de galhas (NG), número de ovos (NO), índice de massas de ovos (IMO), fator de reprodução (FR), redução no fator de reprodução (RFR). Quanto ao desenvolvimento das plantas mensurou-se: altura da planta, massa fresca e seca da parte aérea e massa fresca do sistema radicular. Verificouse que a reprodução do nematoide, mostrou-se menos eficiente em tomate. Os óleos essenciais empregados reduziram a taxa reprodutiva do nematoide em 83 e $29 \%$, em tomate e celósia, respectivamente. As épocas de aplicação dos óleos essenciais diferiram quanto à reprodução do nematoide, para número de galhas e fator de reprodução.

Palavras-chave: controle, agricultura orgânica, Meloidogyne incognita raça 2.

\section{ABSTRACT}

Moreira, F.J.C.; Santos, C.D.G.; Innecco, R.; Silva, G.S. Alternative control of root-knot nematode (Meloidogyne incognita) race 2 with essential oils in soil. Summa Phytopathologica, v.41, n.3, p.207-213, 2015.

The action of natural products on plant pathogens has been investigated with the aim of evaluating their effectiveness in the alternative control of diseases, especially in organic agriculture. The aim of the present study was to evaluate the effect of essential oils of rosemary pepper (Lippia sidoides) and citronella grass (Cymbopogon winterianus) on the control of M. Incognita race 2 , in tomato (Solanum lycopersicum) and celosia (Celosia plicata). Thus, an assay was conducted in $6 \times 2$ factorial arrangement, with five replicates. It was carried out in a greenhouse of the Plant Health Sector of the Department of Phytotechny/CCA/UFC, in the period from April to June 2007. The seedlings used in this test were transplanted into plastic pots containing $2 \mathrm{~kg}$ of sterile soil, in which, at 24 hours after transplanting, 4,000 eggs/J2 of M. incognita, race 2, were inoculated, except for negative controls. For $50 \%$ of the number of pots, $100 \mathrm{ml}$ of the solutions of each essential oil were soon applied to each pot at the concentration of $2.5 \mathrm{ml} \mathrm{L}^{-1}$. After 48 hours, the same amount was applied to the remaining pots. This volume corresponds to $60 \%$ of the field capacity of this substrate, which was previously calculated. The final evaluation was at 45 days after inoculation. The following variables were analyzed in relation to the nematode: number of galls (NG), number of eggs (NE), egg mass index (EMI), reproduction factor (RF), reproduction factor reduction (RFR). Regarding the development of plants, the measured parameters were: plant height, shoot fresh and dry weight, and fresh weight of the root system. The nematode reproduction revealed to be less efficient in tomato. The employed essential oils reduced the reproductive rate of the nematode by 83 and $29 \%$ in tomato and celosia, respectively. The times of application of essential oils differed as to the nematode reproduction for the number of galls and the reproduction factor.

Additional keywords: control, organic agriculture, Meloidogyne incognita race 2.

Os nematoides do gênero Meloidogyne Goeldi (1887) representam os organismos mais evoluídos quanto ao parasitismo de raízes de plantas sendo considerados como um dos principais limitantes da produtividade agrícola. Isso decorre da grande capacidade de adaptação de tais fitoparasitas, em razão de possuírem uma elevada gama de hospedeiros LORDELLO, (17); TIHOHOD, (31); BARKER, (4); FREITAS et al., (13).

Em regiões de clima tropical, as espécies de Meloidogyne spp. 
encontram condições de umidade e temperatura ideais para reprodução. Tais fatores são agravantes para o controle desses fitopatógenos, os quais, após o estabelecimento em uma área são de difícil erradicação e, portanto, exigem medidas que possibilitem a redução populacional para tornar viável o cultivo de determinadas culturas (FREITAS et al., (13); LORDELLO, (17).

O controle dos nematoides das galhas tem sido feito através do uso de diversas táticas, tais como química, física, biológica, mecânica, cultural, etc. (CAMPOS et al., (7). Medidas de controle utilizando plantas resistentes, rotação de culturas com espécies não hospedeiras e o uso de adubos verdes com plantas de efeito antagônico ao nematoide, podem contribuir para a diminuição das populações destes organismos, favorecendo o desenvolvimento das plantas e a produtividade das culturas (COSTA \& FERRAZ, (8); DIAS et al., (9); FERRAZ \& FREITAS, (11). Contudo, estas práticas, muitas vezes, não são utilizadas pelos agricultores, por não apresentarem efeito imediato ou por não darem o retorno econômico equivalente.

Em razão, principalmente, do uso indiscriminado e irresponsável dos agrotóxicos, em geral, tem existido pressões por parte da sociedade para que o uso desses produtos seja cada vez mais restrito (BRASIL, (6). Em vista disso, muitas alternativas de controle tem sido estudadas no sentido de subsidiar os agricultores no manejo seguro de suas lavouras. Dentre as alternativas estudadas, o efeito de extratos botânicos (Dias et al., (10); Amaral et al., (3), exsudados vegetais (Rocha \& Campos, (23) e óleos essenciais (Pandey et al., (21); Oka et al., (19); Oka, (20); Pérez et al., (22); Lopes et al., (16) tem sido frequentemente relatado no controle de fitonematoides.

Os óleos essenciais são potencialmente úteis no manejo de doenças de plantas cultivadas, especialmente na agricultura orgânica, representando uma alternativa a mais na proteção das lavouras (BRASIL, (6); SALGADO et al., (24). O efeito dos óleos essenciais sobre a eclosão e o desenvolvimento de fitonematoides tem sido comprovado (PANDEY et al., (21); OKA et al., (19); OKA, (20); SALGADO \& CAMPOS, (25); PÉREZ et al., (22).

Acrescenta-se a isso o fato de os óleos essenciais possuírem princípios ativos que podem ser úteis na obtenção de compostos tóxicos a nematoides, uma vez que potenciais atividades biológicas que tem sido observadas em alguns constituintes, os quais são de grande interesse para a indústria de defensivos agrícolas. Contudo, o controle de fitonematoides por tal método ainda é incipiente, embora esses produtos sejam seguros ao homem e ao ambiente (SALGADO \& CAMPOS, (25)).

Em estudo realizado com óleo essencial de Capparis flexuosa L., Gonçalves et al., (14) observaram inibição significativa da eclosão de juvenis (J2) de $M$. incognita, na concentração de 1.000 ppm, apresentando atividade nematicida de $97,0 \%$, em relação a testemunha.

Pérez et al., (22) estudando a atividade nematicida de óleos essenciais de várias partes (flores, folhas, raízes e sementes) das plantas de Chrysanthemum coronarium L. e Calendula officinalis L., C. maritima Guss. e C. suffruticosa Vahl. nas concentrações de 10, 20, 30 e $40 \mu \mathrm{L}$ por $500 \mathrm{~cm}^{3}$ de solo sobre a espécie $M$. artiellia, verificaram elevada redução na reprodução do nematoide. Para o desenvolvimento das plantas, os autores não verificaram diferenças entre os tratamentos para a variável altura da planta, evidenciando a ação benéfica dos óleos essenciais.

Os compostos presentes nos óleos essenciais podem atuar diretamente sobre o patógeno ou serem indutores de resistência, envolvendo a ativação de mecanismos de defesa latentes existentes nas plantas (SCHWAN-ESTRADA et al., (26). Contudo, o mecanismo nematicida dos óleos essenciais e seus constituintes ainda não estão esclarecidos (OKA, (20). Muitos testes utilizando óleos essenciais e extratos de plantas medicinais estão sendo realizados no controle dos mais diferentes fitopatógenos. No entanto, até o presente momento, os estudos utilizando compostos extraídos de plantas medicinais tem sido realizados, praticamente, apenas in vitro, sendo necessários estudos em condições de campo (SCHWAN-ESTRADA et al., (26).

Em vista disso, este trabalho teve por objetivo avaliar o potencial nematicida dos óleos essenciais de alecrim pimenta (Lippia sidoides Cham.) e capim citronela (Cymbopogon winterianus Jowitt) em solo, em razão de resultados promissores in vitro, como alternativa para o controle do nematoide das galhas, Meloidogyne incognita raça 2.

\section{MATERIAL E MÉTODOS}

Este ensaio foi realizado em casa de vegetação pertencente ao Setor de Fitossanidade, do Departamento de Fitotecnia, do Centro de Ciências Agrárias, da Universidade Federal do Ceará, em Fortaleza-CE, no período de abril a junho de 2007. A temperatura da casa de vegetação foi monitorada durante o ensaio, com termômetro e apresentou valores médios de $31 \pm 4{ }^{\circ} \mathrm{C}$, respectivamente, com picos de $35^{\circ} \mathrm{C}$ entre $12 \mathrm{e}$ 14 horas.

O solo utilizado neste trabalho constou de substrato preparado com solo e esterco de gado curtido na proporção $3: 1(\mathrm{v} / \mathrm{v})$, peneirado em malha de arame com crivo de $4,0 \mathrm{~mm}$. Todo o substrato foi esterilizado em autoclave vertical por duas horas a $127^{\circ} \mathrm{C}$ e $1,5 \mathrm{~atm}$.

As mudas de tomate (Solanum lycopersicum Mill.) cv. Santa Clara e da planta ornamental celósia (Celosia plicata L.) foram produzidas na própria casa de vegetação, do Setor de Fitossanidade, na quantidade de cinquenta plantas, das quais foram selecionadas 35 de cada espécie, com base na uniformidade das mesmas. Estas espécies vegetais foram selecionadas em razão da suscetibilidade ao patógeno. Quando as mudas apresentavam duas folhas definitivas foram transplantadas, no final da tarde, para vasos plásticos de 2,0 kg de capacidade contendo substrato estéril. Depois de todas as mudas terem sido transplantadas, foi realizada irrigação abundante para minimizar o estresse do transplantio.

A partir de uma cultura monoespecífica de Meloidogyne incognita raça 2, multiplicou-se o patógeno em tomateiros cv. Santa Clara, em casa de vegetação, para emprego como fonte de inóculo.

Os ovos e juvenis (J2) a serem usados como inóculo foram extraídos de raízes galhadas de tomateiro cv. Santa Clara, pela técnica de Hussey \& Barker (1973). Para facilitar a visualização e contagem dos ovos nos testes subsequentes, a suspensão obtida foi submetida ao método de flotação e centrifugação proposto por Jenkins (1964), empregando-se caolim na proporção de 1:10 (v/v) (COOLEN \& D'HERDE, 1972) apud Tihohod (31). A contagem do número de ovos foi realizada com o auxílio de câmara de Peters e de microscópio esteroscópio.

A inoculação dos ovos e $\mathrm{J} 2$ do nematoide no solo foi realizada 24 horas após o transplantio das mudas de tomate e celósia, utilizando-se $4,0 \mathrm{ml}$ de volume de suspensão de forma a se distribuir, igualmente, 4.000 ovos/juvenis por planta. A suspensão foi vertida em três orifícios de profundidade de $1,0 \mathrm{~cm}$ feitos com lápis comum a uma distância de 2-3 cm do caule de cada planta.

Os óleos essenciais de alecrim pimenta e capim citronela foram obtidos de plantas existentes do Horto de Plantas Medicinais da Fazenda Experimental Vale do Curu (FEVC), em Pentecoste - CE, pertencente à Universidade Federal do Ceará. A extração dos óleos essenciais foi realizada por arraste a vapor, conforme metodologia de ALENCAR et al., (1). 
A obtenção da concentração desejada foi feita colocando-se em partes iguais óleo essencial e o detergente Texapon N-40 ${ }^{\circledR}$ (lauril éter sulfato de sódio). Uma vez dissolvido o óleo, acrescentou-se água para a obtenção da concentração de $2,5 \mathrm{ml} \mathrm{L}^{-1}$, sendo esta a diluição utilizada no ensaio. Os óleos essenciais foram diluídos com Texapon N-40 para facilitar a sua solubilização.

Os óleos essenciais diluídos das duas espécies, alecrim pimenta e capim citronela, foram aplicados em duas épocas, sendo a primeira aplicação realizada logo após a inoculação dos ovos/J2 no solo envasado e a segunda realizada 48 horas após a inoculação do nematoide.

O volume do óleo diluído empregado em cada vaso/muda foi de 100 $\mathrm{ml}$ vertidos no solo até atingir a capacidade de campo, de acordo com cálculo efetuado anteriormente. A aplicação foi realizada no final da tarde com o intuito de diminuir o efeito da temperatura, o que poderia acarretar na volatilização rápida dos compostos presentes nos óleos. Não houve repetição da aplicação do óleo diluído.

As varáveis analisadas em relação ao nematoide foram: 1. número de galhas (NG): procedeu-se a contagem das galhas existentes em cada sistema radicular; 2 . número de ovos (NO): os ovos foram extraídos das raízes pela técnica de Hussey \& Barker (1973), apud Tihohod (31), utilizando para facilitar a visualização dos ovos nos testes subsequentes o método de flotação e centrifugação proposto por Jenkins (1964), acrescida de caolim na proporção de 10:1 (v/v) (COOLEN \& D'HERDE, 1972) apud Tihohod (31). A contagem do número de ovos para a calibração da concentração foi realizada com o auxílio de câmara de Peters e de microscópio estereoscópio; 3. índice de massas de ovos (IMO): este índice numérico foi obtido de acordo com a metodologia proposta por Taylor \& Sasser (1978), modificado por Hadisoeganda $\&$ Sasser (1982) o qual emprega uma escala de notas de 0 a 5 , a qual considera o número de galhas ou número de massa de ovos, ou seja, $0=$ $0,1-2=1,3-10=2,11-30=3,31-100=4$ e maior que $100=5 ; 4$. fator de reprodução (FR): foi obtido pelo quociente entre a população final e inicial do nematoide $(\mathrm{FR}=\mathrm{Pf} / \mathrm{Pi}) ; 5$. redução no fator de reprodução (RFR): obteve-se por meio da seguinte fórmula RFR = Frp - Frt / Frp $x$ 100, onde: Frp = fator de reprodução na espécie utilizada como padrão de susceptibilidade; Frt $=$ fator de reprodução no tratamento avaliado.

Quanto ao desenvolvimento das plantas mensurou-se: 1. altura da planta: mediu-se com régua graduada em centímetros, do colo ao ápice da planta; 2. massa fresca da parte aérea: foi realizado em balança digital com precisão de três casas decimais; 3. massa fresca do sistema radicular: foi realizado conforme o item $2 ; 4$. massa seca da parte aérea: obteve-se após as plantas permaneceram por 72 horas em estufa com circulação forçada de ar a temperatura de $80{ }^{\circ} \mathrm{C}$ e pesado conforme o item 2 .

Utilizou-se, nesse ensaio, o delineamento inteiramente casualizado (DIC), em esquema fatorial 6 x 2, sendo seis tratamentos, quais sejam: 1. solo estéril (testemunha negativa); 2. solo infestado com 4.000 ovos/
J2 (testemunha positiva); 3. aplicação de óleo essencial de alecrim pimenta na concentração de $2,5 \mathrm{ml} \mathrm{L}^{-1} \operatorname{logo}$ após a inoculação dos ovos/ $\mathrm{J} 2 ; 4$. aplicação de óleo essencial de alecrim pimenta na concentração de $2,5 \mathrm{ml} \mathrm{L}^{-1} 48$ horas após a inoculação dos ovos/J2; 5. aplicação de óleo essencial de capim citronela na concentração de $2,5 \mathrm{ml} \mathrm{L}^{-1} \log 0$ após a inoculação dos ovos/J2 e 6. aplicação de óleo de capim citronela na concentração de $2,5 \mathrm{ml} \mathrm{L}^{-1} 48$ horas após a inoculação dos ovos/ J2; e duas espécies (tomate e celósia), totalizando 12 tratamentos com cinco repetições de uma planta cada, caracterizando assim a unidade experimental.

Os dados obtidos foram submetidos à análise de variância, a qual foi realizada no programa estatístico Assistat versão 7.4 beta, sendo as variâncias comparadas pelo teste $\mathrm{F}$ ao nível de $1 \%$ de probabilidade. A comparação das médias entre os tratamentos deu-se pelo teste de Tukey ao nível de $1 \%$ de probabilidade, sendo os resultados expressos em Tabelas.

\section{RESULTADOS E DISCUSSÃO}

Na Tabela 1 estão expostos os dados sumarizados da análise de variância a que foram submetidos os dados referentes à infestação do nematoide, quanto ao número de galhas $(\mathrm{NG})$, número de ovos (NO), índice de massa de ovos (IMO), fator de reprodução (FR) e redução do fator de reprodução (RFR). Percebeu-se, então, que para todas as variáveis analisadas houve diferenças estatísticas significativas $(\mathrm{P} \leq$ 0,01 ), exceto para a variável índice de massa de ovos (IMO), tanto para os fatores principais (tratamento com óleos essenciais e espécies) como para a interação (tratamentos com óleos essenciais x espécies).

A análise da Tabela 1 revelou que os óleos essenciais de alecrim pimenta e de capim citronela e as épocas de aplicação afetaram a reprodução do nematoide nas duas espécies vegetais. Estes resultados mostram mais uma vez a eficácia que os óleos essenciais apresentam contra os nematoides, apesar de não de conhecer o mecanismo nematicida destes compostos e seus constituintes (OKA, (20); (SCHWAN-ESTRADA et al., (26).

$\mathrm{Na}$ Tabela 2 estão expostos os valores médios referentes à reprodução do nematoide nas espécies vegetais celósia e tomate, por meio das variáveis número de galhas (NG), número de ovos (NO), índice de massa de ovos (IMO), fator de reprodução (FR) e redução do fator de reprodução (RFR).

Da análise desta Tabela 2, percebeu-se que houve efeito significativo $(\mathrm{P} \leq 0,01)$ quanto aos tratamentos com os óleos diluídos para a variável $\mathrm{NG}$, em relação à testemunha, constatando-se uma diminuição desse número na ordem de $83 \%$ para o tomateiro. Assim, raízes de tomate tratadas com água apresentaram em média 257 galhas, enquanto que tomateiros tratados com óleos de alecrim pimenta, o NG variou de 36

Tabela 1. Dados sumarizados dos quadrados médios e coeficientes de variação a que foram submetidos os dados de número de galhas (NG), número de ovos (NO), índice de massa de ovos (IMO) fator de reprodução (FR), redução do fator de reprodução (RFR) em tomate e celósia inoculados com Meloidogyne incognita raça 2, submetidos a tratamentos com óleos essenciais. Fortaleza-CE. UFC, 2013.

\begin{tabular}{|c|c|c|c|c|c|c|}
\hline \multirow{2}{*}{ Fontes de variação } & \multirow{2}{*}{ G. L. } & \multicolumn{5}{|c|}{ Quadrados médios } \\
\hline & & $\mathrm{NG}$ & $\mathrm{NO}$ & IMO & FR & RFR \\
\hline Tratamentos com óleo (A) & 5 & $39003,7^{*}$ & $207517589,2 *$ & $0,01667^{\mathrm{NS}}$ & $12,83^{*}$ & $3871,5^{*}$ \\
\hline Espécies (B) & 1 & $47489,0^{*}$ & $619569227,2 *$ & $0,05667^{\mathrm{NS}}$ & $39,20 *$ & $11985,0^{*}$ \\
\hline Interação (A x B) & 5 & $77876,9^{*}$ & $416461739,8^{*}$ & $0,0667^{\mathrm{NS}}$ & $25,91^{*}$ & $7905,8^{*}$ \\
\hline Resíduo & 48 & 406,0 & 1265276,1 & 0,0833 & 0,07 & 6,3 \\
\hline C. V. $(\%)$ & - & 17,6 & 18,0 & 5,8 & 17,7 & 3,5 \\
\hline
\end{tabular}

* valor significativo pelo teste de Tukey $(\mathrm{P} \leq 0,01)$. 
Tabela 2. Valores médios de número de galhas, número de ovos, índice de massa de ovos, fator de reprodução e redução do fator de reprodução em tomate e celósia inoculadas com M. incognita, raça 2, submetidos a tratamentos com óleos essenciais. Fortaleza-CE. UFC, 2013.

\begin{tabular}{|c|c|c|c|c|c|c|}
\hline \multirow{2}{*}{ Espécies } & \multicolumn{6}{|c|}{ Tratamentos } \\
\hline & $\mathrm{SE}^{*}$ & SI & $\mathrm{A} 0$ & $\mathrm{~A} 48$ & $\mathrm{C} 0$ & $\mathrm{C} 48$ \\
\hline & \multicolumn{6}{|c|}{ 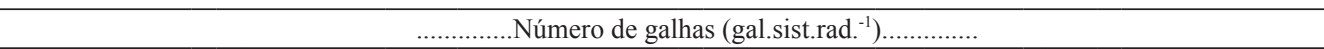 } \\
\hline Tomate & $0,0 \mathrm{eA} * *$ & $257 \mathrm{aA}$ & $59 \mathrm{bB}$ & $36 \mathrm{~dB}$ & $46 \mathrm{cB}$ & $32 \mathrm{~dB}$ \\
\hline \multirow[t]{2}{*}{ Celósia } & $0,0 \mathrm{cA}$ & $284 \mathrm{aA}$ & $205 \mathrm{bA}$ & $187 \mathrm{bA}$ & $207 \mathrm{bA}$ & $204 \mathrm{bA}$ \\
\hline & \multicolumn{6}{|c|}{ 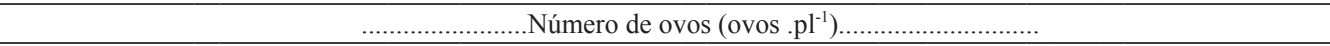 } \\
\hline Tomate & $0,0 \mathrm{dA}$ & $21.698 \mathrm{aA}$ & $2.079 \mathrm{bB}$ & $1.246 \mathrm{cB}$ & $1.596 \mathrm{cB}$ & $1.134 \mathrm{cB}$ \\
\hline \multirow[t]{2}{*}{ Celósia } & $0,0 \mathrm{cA}$ & $23.997 \mathrm{aA}$ & $7.189 \mathrm{bA}$ & $7.428 \mathrm{bA}$ & $7.231 \mathrm{bA}$ & $7.154 \mathrm{bA}$ \\
\hline & \multicolumn{6}{|c|}{ 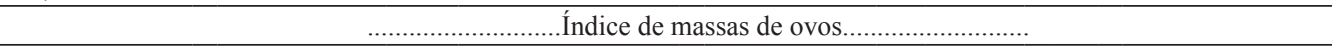 } \\
\hline Tomate & $0,0 \mathrm{bA}$ & $5,0 \mathrm{aA}$ & $5,0 \mathrm{aA}$ & $5,0 \mathrm{aA}$ & $5,0 \mathrm{aA}$ & $5,0 \mathrm{aA}$ \\
\hline \multirow[t]{2}{*}{ Celósia } & $0,0 \mathrm{bA}$ & $5,0 \mathrm{aA}$ & $5,0 \mathrm{aA}$ & $5,0 \mathrm{aA}$ & $5,0 \mathrm{aA}$ & $5,0 \mathrm{aA}$ \\
\hline & \multicolumn{6}{|c|}{ 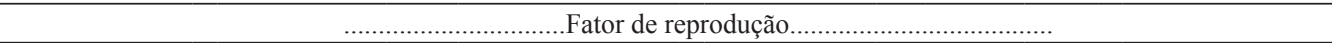 } \\
\hline Tomate & $0,0 \mathrm{eA}$ & $5,4 \mathrm{aA}$ & $0,5 \mathrm{bB}$ & $0,3 \mathrm{~dB}$ & $0,4 \mathrm{cB}$ & $0,3 \mathrm{~dB}$ \\
\hline \multirow[t]{2}{*}{ Celósia } & $0,0 \mathrm{dA}$ & $6,0 \mathrm{aA}$ & $1,8 \mathrm{bA}$ & $1,9 \mathrm{cA}$ & $1,8 \mathrm{bA}$ & $1,8 \mathrm{bA}$ \\
\hline & \multicolumn{6}{|c|}{ 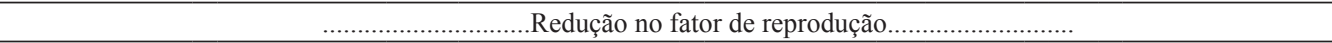 } \\
\hline Tomate & $100 \mathrm{aA}$ & $0,0 \mathrm{cC}$ & $90,4 \mathrm{bA}$ & $94,2 \mathrm{bA}$ & $92,6 \mathrm{bA}$ & $94,8 \mathrm{bA}$ \\
\hline Celósia & $100 \mathrm{aA}$ & $0,0 \mathrm{cC}$ & $70,0 \mathrm{bB}$ & $70,0 \mathrm{bB}$ & $69,9 \mathrm{bB}$ & $70,2 \mathrm{bB}$ \\
\hline
\end{tabular}

*SE $=$ solo estéril; $\mathbf{S I}=$ solo infestado com 4.000 ovos $/ \mathbf{J} 2 ; \mathbf{A 0}=$ óleo essencial de alecrim pimenta aplicado logo após a inoculação; $\mathbf{A 4 8}=$ óleo essencial de alecrim pimenta aplicado 48 horas após a inoculação; $\mathbf{C 0}=$ óleo essencial de capim citronela aplicado logo após a inoculação; $\mathbf{C 4 8}=$ óleo essencial de capim citronela aplicado 48 horas após a inoculação.

** médias de mesma letra minúscula na linha e maiúscula na coluna não diferem entre si pelo teste de Tukey 1\% de probabilidade.

a 59, e com o capim citronela o NG variou de 32 a 46 galhas.

Em celósia, observou-se que a redução dessa variável foi inferior, na faixa de $29 \%$, com o NG diminuindo de 284 , contatas nas raízes da testemunha, para 187 e 205 em plantas tratadas com o óleo de alecrim pimenta, e de 204 a 207, nas raízes de celósia tratadas com o óleo do capim citronela (Tabela 2).

Na observação da variável NO (Tabela 2), observou-se que houve uma drástica redução na reprodução do nematoide quando comparado com as testemunhas. Quando se utilizou apenas água no solo o NO nas raízes de tomate foi de 21.698 e nas de celósia foi de 23.997. Nos tratamentos do solo com os óleos essenciais de alecrim pimenta esse número foi de 1.246 e 2.079 para tomate, e de 7.189 e 7.428 para celósia, respectivamente. Com o óleo do capim citronela a redução do NO foi de 1.134 e 1.596 para tomate, e de 7.154 e 7.231 para celósia, respectivamente.

Para a variável IMO, percebeu-se que não houve diferença significativa entre nenhum tratamento, nem mesmo com a testemunha. Isso, provavelmente ocorreu em função da forma de obtenção dessa variável, a qual é feita por meio de uma escala de notas, atribuindose a nota 5 para todas as plantas que apresentassem em seu sistema radicular um número de massas de ovos superior a 100. Isso aconteceu em todas as plantas analisadas, razão de todas receberem a nota 5,0. Contudo, ressalta-se que o número de massa de ovos nas testemunhas, como citado anteriormente, era superior a 21 galhas.

Ainda na Tabela 2, quando se analisou a variável FR, constatou-se que a aplicação dos dois óleos essenciais no solo infestado foi eficaz, reduzindo a reprodução do nematoide. Contudo, verificou-se que em tomate esta redução foi mais efetiva, pois o FR de todos os tratamentos foi inferior a um $(0,5 ; 0,3 ; 0,4$ e 0,3$)$, enquanto nas plantas de celósia o FR foi superior a um $(1,8 ; 1,9 ; 1,8$ e 1,8$)$, em relação às testemunhas, 5,4 e 6,0 , respectivamente.

Para a variável RFR, verificou-se que entre as espécies tomate e celósia houve diferença significativa, com o tomate mostrando, mais uma vez, melhores resultados, ou seja, com valores médios de RFR de $93,0 \%$ enquanto que em celósia ao RFR foi de 70,0\% (cálculos não apresentados). Os valores do RFR de tomate e celósia nas plantas testemunhas (água) foram utilizados na fórmula como a o fator de reprodução padrão e, por esta razão, são apresentados com o 0,0 na Tabela 2 .

Nos tratamentos com óleo de alecrim pimenta no solo com tomateiros, a RFR foi de 90,4 e 94,2\%, e no solo com celósia a RFR foi de $70 \%$. Empregando-se óleo diluído do capim citronela em solo com tomateiros a RFR foi de 92,6 e 94,8, e no solo com a celósia, o RFR nas raízes foi de 69,9 e 70,2\%. Constatou-se, com esses resultados, que a RFR foi sempre superior em tomateiros, independente do óleo aplicado.

Analisando-se as épocas de aplicação dos óleos, notou-se também que a adoção de um intervalo de zero (0) horas ou de 48 horas após a inoculação do nematoide, foi estatisticamente significativa. As aplicações realizadas 48 horas após a inoculação foram mais efetivas para tomate que para celósia. Em tomateiro, empregando-se o óleo de alecrim pimenta no solo após 48 horas, constatou-se uma maior redução no NG, NO e no FR. Com o óleo de capim citronela, apesar de NO semelhante, houve redução do NG e FR. Para a celósia, os valores das variáveis, foram semelhantes independente do óleo aplicado como também da época de aplicação ao solo infestado.

As variáveis IMO e RFR, tanto para tomate como para celósia, não apresentaram valores com diferenças significativas, independente do óleo aplicado e da época de aplicação ao solo infestado.

A redução do número de galhas, número de ovos, índice de massa de ovos e conseqüentemente, do fator de reprodução e redução fator de reprodução do nematoide pode ter ocorrido pelo contato direto dos óleos essenciais no solo com ovos e, ou J2, o que proporcionaria uma ação direta sobre estes organismos.

As significativas reduções observadas na reprodução do nematoide das galhas, ocorridas em consequência da aplicação dos óleos essenciais, podem se dever, provavelmente, às substâncias bioativas presentes nestes óleos, pois, segundo estudos, estes apresentam na sua constituição, compostos caracterizados como o cineol, citral, geraniol, eugenol, cariofileno e linalol, os quais possuem efeitos bactericida, inseticida e anti-sépticos comprovados e provavelmente com alguma 
ação sobre os nematoides (OKA et al., (19); SERAFINI \& CASSEL, (27); SIMÕES et al., (29); FREIRE et al., (12); MATOS et al., (18).

Segundo Schawn-Estrada et al., (26), os princípios ativos existentes nos óleos essenciais podem atuar diretamente sobre a cutícula do patógeno, alterando sua permeabilidade ou então, possuírem mecanismos indutores de resistência envolvendo a ativação de estruturas de defesa latentes existentes nas plantas.

De acordo com Lopes et al., (16), os compostos dos óleos essenciais aplicados nas plantas podem promover a liberação via exsudação das raízes, sejam estas por modificações enzimáticas na planta, seja por alterações fisiológicas ocorridas nas raízes, atuando contra os nematoides.

Bosenbecker (5), estudando o efeito dos óleos essenciais de eucalipto (Eucalyptus globulus Labill.) e funcho (Foeniculum vulgare) no controle de Phytophthora infestans e Meloidogyne javanica em batata (Solanum tuberosum L.), observou diminuição na formação de colônias, alcançando $100 \%$ na concentração de 1.500 ppm e para $M$. incognita, o autor observou redução de $90 \%$ de eclosão de juvenis na concentração de $1.500 \mathrm{ppm}$. Contudo, a forma como tais compostos realmente agem sobre o patógeno ainda é fato desconhecido, e há necessidade de mais estudos para serem elucidadas.

Pérez et al., (22) estudando a atividade nematicida óleos essenciais de várias partes (flores, folhas, raízes e sementes) das plantas de Chrysanthemum coronarium L. e Calendula officinalis, C. maritima e C. suffruticosa em M. artiellia, nas concentrações de 10, 20, 30 e 40 $\mu \mathrm{L}$ por $500 \mathrm{~cm}^{3}$ de solo, observaram elevada redução na reprodução desse nematoide. Contudo, para o desenvolvimento das plantas, não houve diferenças entre os tratamentos para a variável altura da planta. Os autores não comentam sobre possíveis modos de ação dos óleos essenciais.

Em trabalho realizado em solo, Alcanfor (2), estudando uma formulação com os princípios ativos (timol e cineol), obteve eficiente controle de $M$. incognita em tomateiros, porém, numa concentração de $20 \mathrm{ml} \mathrm{L}^{-1}$, ou seja, cerca de oito vezes superior a que se empregou neste trabalho com resultado de $100 \%$ de inibição da eclosão, in vitro, com os óleos de alecrim pimenta e capim citronela, espécies estas que apresentam entre seus constituintes majoritários o timol e cineol, respectivamente. Logo, os dados obtidos por aquele autor sugerem que a quantidade de óleo a ser utilizada para ensaios no solo sejam superiores àquelas utilizadas in vitro.

Na Tabela 3, está exposto o resumo da análise de variância a que foram submetidos os dados alusivos ao desenvolvimento das duas espécies estudadas, referentes à altura da planta (AP), massa fresca da parte aérea (MFPA), massa fresca do sistema radicular (MFSR) e massa seca da parte aérea (MSPA).

Verificou-se que, para todas as variáveis analisadas, em relação aos tratamentos com os óleos para o controle do nematoide, houve diferenças estatísticas significativas $(\mathrm{P} \leq 0,01)$. Para as espécies estudadas, apenas a altura da planta mostrou-se com diferença significativa $(\mathrm{P} \leq 0,05)$.

A interação (tratamentos com os óleos $\mathrm{x}$ espécies) evidenciou diferença significativa apenas para a variável altura da planta $(\mathrm{P} \leq 0,01)$. Assim, percebeu-se que os óleos essenciais mostraram-se efetivos, favorecendo o crescimento das plantas em relação às testemunhas positivas.

Na Tabela 4 estão expostos os valores médios referentes às variáveis que expressam o desenvolvimento das plantas quanto à altura das plantas, massa fresa da parte aérea, massa seca da parte aérea e massa fresca do sistema radicular.

Nessa mesma Tabela, para a variável altura da planta, constatou-se que nos tratamentos com os óleos essenciais, o desenvolvimento das plantas de celósia foi superior em relação à testemunha positiva (plantas inoculadas e sem tratamento com os óleos essenciais), porém um pouco inferior às plantas crescidas em solo estéril.

As épocas de aplicação também influenciaram no desenvolvimento das plantas de celósia. Sua altura média foi de 91 e $82,7 \mathrm{~cm}$, nos vasos em que os óleos essenciais de alecrim pimenta e capim citronela, respectivamente, foram aplicados após 48 horas da inoculação. A altura das plantas de celósia com os óleos de alecrim pimenta e capim citronela aplicados ao solo logo após inoculação (zero hora) foi de 81 e $76 \mathrm{~cm}$, respectivamente. A altura das plantas de celósia foi de $62,7 \mathrm{~cm}$ em solo infestado sem tratamento e de $108,7 \mathrm{~cm}$ nas plantas em solo estéril.

Ressalta-se que o aspecto vigoroso das plantas de celósia foi observado, em todos os tratamentos com os óleos, mesmo havendo um desenvolvimento satisfatório do nematoide, com sistemas radiculares com elevado número de galhas, relativamente atrofiados, debilitados e com poucas raízes secundárias, aspecto que a fazem considerar uma espécie, aparentemente, tolerante ao parasitismo desse nematoide.

Contudo, para o tomate não se verificou o mesmo resultado, ou seja, as plantas infectadas mantidas em solo com aplicação ou não dos óleos apresentaram alturas semelhantes, porém inferiores àquelas não inoculadas (solo estéril) (Tabela 4).

Para as variáveis massa fresca da parte aérea, massa seca da parte aérea e massa fresca do sistema radicular (Tabela 4), verificou-se que não houve efeito significativo dos tratamentos com os óleos essenciais de alecrim pimenta e capim citronela. Os valores dessas variáveis nos tomateiros infectados foram também semelhantes quando comparados às duas testemunhas, infectada e sadia.

Os resultados obtidos neste trabalho, com os óleos, nas concentrações utilizadas e época de aplicação, apesar de mostrarem redução na reprodução do nematoide, não podem ainda ser considerados satisfatórios para um programa de manejo recomendado para horticultores e produtores de plantas ornamentais e medicinais.

O insucesso do emprego dos óleos no controle efetivo do $M$.

Tabela 3. Dados sumarizados dos quadrados médios e coeficientes de variação a que foram submetidos os dados de altura da planta (AP), massa fresca (MFPA) e seca da parte aérea (MSPA) e massa fresca do sistema radicular (MFSR) em tomate e celósia inoculadas com M. incognita, raça 2, submetidos a tratamentos com óleos essenciais. Fortaleza-CE. UFC, 2013.

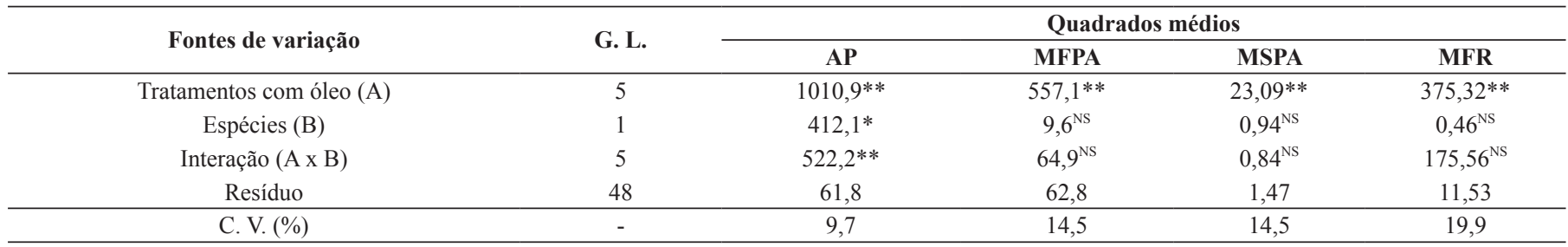

* e** valores significativos a 1 e $5 \%$ de probabilidade pelo teste de Tukey, respectivamente. $\mathrm{NS}=$ valor não significativo. 
Tabela 4. Valores médios de altura das plantas, massa fresca e seca da parte aérea e massa fresca do sistema radicular em tomate e celósia inoculadas com M. incognita raça 2, submetidos a tratamentos com óleos essenciais. Fortaleza-CE. UFC, 2013.

\begin{tabular}{|c|c|c|c|c|c|c|c|}
\hline Espécies & \multicolumn{6}{|c|}{ Tratamentos } & - Médias \\
\hline Tomate & $77,9 a b^{* *}$ & $75,2 \mathrm{aA}$ & $76,6 \mathrm{aA}$ & $82,3 \mathrm{aB}$ & $68,6 \mathrm{aB}$ & $61,2 \mathrm{aB}$ & 73,6 \\
\hline \multirow[t]{2}{*}{ Médias } & 93,3 & 68,9 & 78,8 & 86,7 & 72,6 & 72,0 & - \\
\hline & \multicolumn{7}{|c|}{ 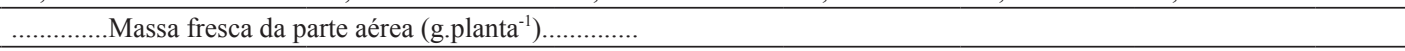 } \\
\hline Tomate & 63,5 & 63,8 & 56,0 & 64,1 & 59,3 & 58,0 & $60,6 \mathrm{~A}$ \\
\hline Médias & \multicolumn{7}{|c|}{ 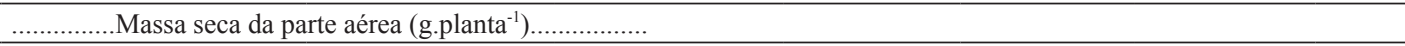 } \\
\hline Tomate & 8,2 & 8,2 & 7,5 & 7,8 & 8,0 & 7,9 & $7,9 \mathrm{~A}$ \\
\hline Celósia & 6,0 & 4,7 & 5,7 & 5,8 & 5,0 & 4,5 & $5,3 \mathrm{~B}$ \\
\hline \multirow[t]{2}{*}{ Médias } & $7,1 \mathrm{~A}$ & $6,5 \mathrm{~A}$ & $6,6 \mathrm{~A}$ & $6,8 \mathrm{~A}$ & $6,5 \mathrm{~A}$ & $6,1 \mathrm{~A}$ & - \\
\hline & \multicolumn{7}{|c|}{...........Massa fresca do sistema radicular $\left(\right.$ g.planta $\left.^{-1}\right) \ldots \ldots \ldots . .}$. \\
\hline
\end{tabular}

*SE = solo estéril; $\mathbf{S I}=$ solo infestado com 4.000 ovos/J2; $\mathbf{A 0}=$ óleo essencial de alecrim pimenta aplicado logo após a inoculação; A48 = óleo essencial de alecrim pimenta aplicado 48 horas após a inoculação; $\mathbf{C} \mathbf{0}=$ óleo essencial de capim citronela aplicado logo após a inoculação; $\mathbf{C 4 8}=$ óleo essencial de capim citronela aplicado 48 horas após a inoculação. ** médias de mesma letra minúscula na linha e maiúscula na coluna não diferem entre si pelo teste de Tukey $1 \%$ de probabilidade.

incognita raça 2 in vivo, provavelmente ocorreu em virtude de uma possível volatilização de seus compostos no solo descoberto ou em razão de interações existentes no solo entre os óleos essenciais e seus constituintes, reduzindo a ação sobre o patógeno, conforme se observou ocorrer in vitro.

No entanto, são necessários estudos subseqüentes, com os quais será possível a validação do uso eficaz e seguro desse tipo de produto natural, otimizando seus resultados e contribuindo assim, para uma agricultura saudável, sustentável, eliminando os efeitos insalubres que o homem e o ambiente estão sujeitos com a utilização dos defensivos agrícolas de síntese.

Os óleos essenciais aplicados ao solo reduziram a reprodução do nematoide nas duas espécies testadas;

Não houve diferença entre os intervalos de aplicação dos óleos essenciais;

A taxa reprodutiva do nematoide foi reduzida em 83 e $29 \%$, em tomate e celósia, respectivamente.

\section{REFERÊNCIAS}

1. Alencar, J.W.; Craveiro, A.A.; Matos, F.J.A. Kovats' indeces as a presetection routine in mass spectra library searches of volatiles. Journal of Natural Products, v.47, n. 05, p. 890-892, 1984.

2. Alcanfor, D.C. Uso de produtos naturais no controle de nematoide das galhas (Meloidogyne incognita) com produtos naturais em tomate (Lycopersicon esculetum Mill.). 83 f. 2004. Dissertação (Mestrado em Agronomia). Universidade Federal do Ceará. Fortaleza-CE.

3. Amaral, D.R.; Oliveira, D.F.; Campos, V.P. Carvalho, D.A. Efeito de extratos vegetais na eclosão, mobilidade, mortalidade e patogenicidade de Meloidogyne exigua do café. Nematologia Brasileira. v. 26. n. 1. P. 43-48. 2002.

4. Barker, K.R. Perspectives on plant and soil nematology. Annual Review of Phytopathology, v. 41, p. 1-25, 2003.

5. Bosenbecker, V.K. Efeitos de óleos essenciais de plantas bioativas no controle de Phytophthora infestans e Meloidogyne javanica em batata (Solanum tuberosum L.). 65 f. 2006. Tese (Doutorado em Agronomia) Universidade Federal de Pelotas, Pelotas-RS.

6. BRASIL. Constituição Federal. Lei no 10.831, de 23 de dezembro de 2003. (Lei dos Orgânicos). 2003.
7. Campos, V.P.; Campos, J.R.; Silva, L.H.C.P.; Dutra, M.R. Manejo de nematoides em hortaliças. In: SILVA, L.H.C. P.; CAMPOS, J.R.; NOJOSA, G.B.A. Manejo integrado: doenças e pragas em hortaliças. Lavras: UFLA, p. 125-158. 2001.

8. Costa, D.S.C.; Ferraz, S. Avaliação do efeito antagônico de algumas espécies de plantas, principalmente de inverno, a Meloidogyne javanica. Nematologia Brasileira. v. 14, p. 61-69, 1990.

9. Dias, C.R.; Ribeiro, R.C.F.; Ferraz, S.; Vida, J.B. Efeito de frações de esterco bovino na eclosão de juvenis de Meloidogyne incognita. Nematologia Brasileira, v. 23, p. 34-39, 1999.

10. Dias, C.R.; Schawn-Estrada, A.V.; Ezeqiel, D.P.; Sarmento, M.C.; Ferraz, S. Efeito de extratos aquosos de plantas medicinais na sobrevivência de juvenis de Meloidogyne incognita. Nematologia Brasileira, v. 24, n. 2, p. 203-210, 2000.

11. Ferraz, S.; Freitas, L.G. de. O controle de fitonematoides por plantas antagonistas e produtos naturais. Disponível em: $<\mathrm{http}: / / \mathrm{www} . u f v . b r / \mathrm{dfp} /$ lab/nematologia/antagonistas.pdf $>$. Acesso em: 12 de novembro de 2006.

12. Freire, A.R.; Andrade Neto, M.A.; Silva, M.G. V. Matos, F.J.A. Avaliação dos óleos essenciais de Ocomum gratissimum L., Ocimum micranthum Willd. e Ocimum tenuiflorum L. como fitonematicida. In: Simpósio Brasileiro de Óleos Essenciais, 2. (Documentos, IAC, 74). Campinas, p. 107. 2003.

13. Freitas, L.G.; Oliveira, R.D.L.; Ferraz, S. Introdução à Nematologia. Viçosa: UFV, 84p. 2004.

14. Gonçalves, F.J.T.; Freire, F.C.O.; Andrade Neto, M. Atividade antagonista do óleo essencial dos frutos de Capparis flexuosa em ovos de juvenis de Meloidogyne incognita. In: Congresso Brasileiro de Defensivos Agrícolas Naturais, 1. COBRADAN. Fortaleza. 2000. Anais... Fortaleza: CE. UFC, v. 1. p. 35. 2000.

15. Hadisoeganda, W.W.; Sasser, J.N. Resistence of tomato, bean, southern pea and garden pea cultivars to root-knot nematodes based on host suitability. Plant Disease. v. 66, n. 2. p. 145-149. 1982.

16. Lopes, E.A.; Ferraz, S.; Freitas, L.G.; Ferreira, P.A.; Amora, D.X. Efeito dos extratos aquosos de Mucuna preta e de Manjericão sobre Meloidogyne incognita e M. javanica. Nematologia Brasileira, v. 29, n. 1, p. 67-74, 2005.

17. Lordello, L.G.E. Nematoides de plantas cultivadas. $9^{\text {a }}$ ed. São Paulo. Nobel. 356p. 1992.

18. Matos, F.J.A.; Sousa, M.P.; Matos, M.E.O.; Machado, M.I.L.; Craveiro, A.A. Constituintes químicos ativos e propriedades biológicas de plantas medicinais brasileiras. Editora UFC. $2^{\mathrm{a}}$ Ed. Fortaleza. 448p. 2004.

19. Oka, Y.; Nacar, S.; Putievsky, E.; Ravid, U.; Yaniv, Z.; Spiegel, Y. Nematim cidal activity of essential oils and their components against the root-knot nematode. Nematology. v. 90, n. 7. p. 710-715, 2000. 
20. Oka, Y. Nematicidal activity of essential oil components against the root-knot nematode Meloidogyne javanica. Nematology, v. 3, n. 2, p. 159-164, 2001.

21. Pandey, R.; Karla, A.; Tandon, S.; Mehrotra, N.; Singh, H.N.; Kumar, S. essential oils as potent sources of nematicidal compounds. Journal of Phitopathology. v. 148, p.501-502. 2000.

22. Pérez, M.P.; Navas-Cortés, J.A.; Pascual-Villalobos, M.J.; Castillo, P. Nematicidal activity of essential oils and organic amendments from Asteraceae against root-knot nematodes. Plant Pathology. n. 52. p. 395-401. 2003.

23. Rocha, F.S.; Campos, V.P. Efeito de exsudatos de cultura de células de plantas em juvenis de segundo estádio de Meloidogyne incognita. Fitopatologia Brasileira, v. 29, n. 3, p. 294-299, 2004.

24. Salgado, S.M.L.; Campos, V.P.; Cardoso, M.G.; Salgado, A.P.S. Eclosão e mortalidade de juvenis de segundo estádio de Meloidogyne exigua em óleos essenciais. Nematologia Brasileira, v. 27, n. 1, p. 17- 22, 2003.

25. Salgado, S.M.L.; Campos, V.P. Eclosão e mortalidade Meloidogyne exigua em extratos e em produtos naturais. Fitopatologia Brasileira. v. 28. n. 2. p. $166-170.2003$.
26. Schwan-Estrada, K.R.F.; Stangarlin, J.R.; Cruz, M.E.S. Uso de plantas medicinais no controle de doenças de plantas. Mesa Redonda do XXXVI Congresso Brasileiro de Fitopatologia. Uberlândia: Fitopatologia Brasileira, v. 28, p. 554-556, 2003.

27. Serafini, L.A.; Cassel, E. Produção de óleos essenciais: uma alternativa para a agroindústria nacional. Guaíba: Agroindústria, p.333377. 2001.

28. Silva, J.F.V. (organizador). Ferraz, L.C.C.B.; Asmus, G.L.; Carneiro, R.G.; Mazaferra, P.; Silva, J.F.V. Relações parasito-hospedeiro nas meloidoginoses da soja. Londrina: Embrapa soja. Sociedade Brasileira de Nematologia. 127p. 2001.

29. Simões, C.M.O.; Schenkel, E.P.; Gosmann, G.; Mello, J.C.P. de; Mentz, L.A.; Petrovick, P. R. Farmacognosia: da planta ao medicamento. $5^{\circ}$ ed. Porto Alegre, UFRGS. Florianópolis, UFSC. 1104p. 2003.

30. Taylor, A.L.; Sasser, J.N. Biology, identification and control of rootknot nematodes (Meloidogyne species). Raleigh: North Caroline State Un. Graphics. 111p. 1978.

31. Tihohod, D. Nematologia agrícola aplicada. Jaboticabal: FUNEP. 372 p. 1993. 